\title{
FAMÍLIA, ESCOLA E JUVENTUDE NOS DEBATES SOBRE A CULTURA CONTEMPORÂNEA
}

DAYRELL, J. et al. (Org.). Família, escola e juventude: olhares cruzados Brasil-Portugal. Belo Horizonte: Ed.UFMG, 2012. 449 p.

A coletânea aqui resenhada é fruto do I Colóquio Luso-Brasileiro de Sociologia da Educação, realizado em 2008, em Belo Horizonte. O livro está dividido em duas partes e os artigos são ligados por eixos temáticos. A seção intitulada A família na sociedade contemporânea é composta pelos eixos A legitimidade cultural no mundo contemporâneo, A relação família-escola na contemporaneidade e As pesquisas sobre o efeito do estabelecimento de ensino; já a segunda seção, intitulada Juventude contemporânea e educação, tem os eixos Juventude e cotidiano escolar, Juventude, cultura e ações coletivas, Juventude e diversidade: raça/etnia, gênero e sexualidade. Ao todo, são 20 artigos elaborados por pesquisadores portugueses e brasileiros.

O maior mérito do livro é sua perspectiva internacional e mesmo não havendo abordagens comparativas nos artigos o leitor é capaz de encontrar similaridades teóricas, conceituais e empíricas que aproximam os pesquisadores e perceber consonâncias entre famílias, escolas e a juventude brasileira e a portuguesa.

A primeira seção, que tem como focos a escola e a família, prioriza o debate sobre a pertinência da teoria de Pierre Bourdieu sobre cultura legítima e o papel legitimador da escola em relação ao habitus e à illusio que reproduzem a cultura dominante. Os autores desta seção ressaltam que no mundo globalizado o determinismo do capital escolar deve ser relativizado, pois hoje os jovens recebem a influência de múltiplos agentes de socialização, criando habitus "plásticos" e "híbridos".

\footnotetext{
*Doutora em Antropologia Social, Universidade de São Paulo (USP); Professora Associada do Programa de Pós-graduação em Extensão Rural, Universidade Federal de Viçosa (UFV); Coordenadora do Observatório da Juventude Rural, Universidade Federal de Viçosa (UFV). E-mail: sheila@ufv.br
} 
Os argumentos utilizados pelos autores residem na constatação de que as formas e os conteúdos do repertório cultural na contemporaneidade não são mais ditados e transmitidos apenas por instituições tradicionais mas também por novas matrizes e autoridades culturais que emergem e passam a desempenhar outras modalidades educativas e socializadoras, retirando da família e da escola o monopólio na formação das disposições de habitus juvenis. Alguns dos autores sustentam que a cultura de massa, as novas tecnologias da comunicação e da informação e a maior possibilidade de intercâmbios internacionais para a complementação escolar são alguns dos fatores que ajudam a construir um ambiente favorável à difusão de valores e padrões de conduta diversificados, intensificando as mediações culturais que expandem as disposições mentais e as práticas, particularmente dos jovens.

A família, nesse sentido, também participa desse cosmopolitismo, o que, segundo alguns autores, pode servir de argumento para a dificuldade de definir claramente o que seria hoje a cultura dominante e qual o papel da escola na sua transmissão. As diferentes classes sociais, devido à circulação mais intensiva de informação, saberes e gostos, apresentam um "consumo onívoro", ou seja, maior interesse e tolerância com a diversidade cultural, borrando as barreiras antes marcadas com nitidez entre o estilo popular e o erudito, entre legítimo e ilegítimo. A falta de uma cultura ou de espaços culturais homogêneos na contemporaneidade leva alguns autores a preferirem o termo hibridação, formulado por Garcia Canclini, que melhor definiria essas experiências alargadas e difusas de socialização.

No entanto, se essa nova configuração cultural é indispensável quando analisamos a quebra da hegemonia da escola como instituição matricial na manutenção da ideologia dominante - e que para alguns sequer é possível localizar -, há outros autores que argumentam que as próprias oportunidades trazidas pela globalização atuam como forma de distinção social entre os alunos e suas famílias, e também entre as próprias escolas. Assim, eles defendem uma relativização na análise do enfraquecimento do poder da escola.

Dois pontos merecem destaque nesses argumentos. $\mathrm{O}$ primeiro diz respeito à aproximação das famílias do destino das escolas, promovida inclusive por políticas públicas que conclamam a forma participativa de acompanhamento familiar do cotidiano escolar. Muitas vezes fonte de conflito entre escola, família e aluno, o fato é que nessa participação mais intensa os 
pais criam e cobram estratégias diferenciadas para que a escola incorpore a nova plasticidade do habitus e gere certos investimentos educacionais que preparem a identidade e capacidade dos filhos como cidadãos do século XXI, multiculturais e mundializados. Dentro da escola, a pressão dos pais é visível no monitoramento da vida escolar, inclusive do desempenho de professores, no acompanhamento dos deveres e programação extraescolar, na participação nas instâncias administrativas, pelo maior acesso a informações sobre o sistema escolar e pela maior capacidade de avaliar diferentes propostas pedagógicas.

Quando a escola não corresponde a esses desafios, os próprios pais sofisticam a complementação educacional, canalizando investimentos para a aquisição de um capital social e cultural diferenciado, seja através da internacionalização da formação e da carreira dos filhos, seja através da criação de competências exigidas pelo novo contexto mundial: autonomia, aptidões linguísticas, cultura geral e especializada, mobilidade e adaptabilidade. Assim, alguns autores ressaltam que a formação dos filhos, ainda vista pelo prisma utilitarista, recebe por parte da família benefícios variáveis conforme a classe social, refletindo novas formas de distinção que podem influenciar, principalmente, a melhor inserção futura nas oportunidades globalizadas.

O segundo ponto do argumento refere-se ao sistema de ranking das escolas, presente em Portugal e no Brasil, que acaba conferindo status privilegiado e maior legitimidade para algumas escolas, envolvendo professores, pais e alunos num patamar de competição que possibilita retomar, analiticamente, a importância da escola no desempenho social dos seus alunos. Assim, exames oficiais como Enem, Prova Brasil ou Enade permitem entrever manobras estratégicas por parte das escolas e das famílias para destacar e segregar instituições escolares das classes altas e médias. Melhores investimentos na escola, decorrentes da maior participação familiar no universo escolar e também da maior autonomia das escolas, incluem até mesmo formular critérios de triagem e seleção dos "melhores", ou seja, as famílias empregam o capital econômico e social que possuem em prol de um contexto escolar elitizado, o que faz com que a escola ressoe interesses particulares e continue como instituição entrecruzada pelas desigualdades sociais. Assim, a chamada "crise da escola" pode ser analisada, também, pelos conflitos entre visões divergentes sobre o papel da escola na inclusão, na justiça social e na igualdade de oportunidades. 
A segunda seção do livro focaliza mais especificamente os processos de socialização que formam o universo cultural e político juvenil em espaços não escolares. Uma das questões principais dos autores reside em analisar o papel da escola e de outras instâncias socializadoras na construção das noções e das práticas de cidadania e de civilidade junto aos jovens, e para isso eles recorrem às contribuições teóricas da sociologia da educação e da sociologia da juventude. Assim, o debate focaliza outras dimensões da inserção juvenil nos espaços públicos, suas várias fontes de sociabilidade, notadamente as intrageracionais, fatores que influenciam a relação juvenil com a escola e relativizam a condição dos jovens somente como alunos.

Quatro discussões parecem centrais nesses artigos: construção biográfica dos jovens, microculturas e resistências juvenis, autonomia e passagem para a vida adulta.

Corroborando ideias já abordadas na seção anterior, os autores enfatizam que a plasticidade dos novos meios de socialização e as múltiplas fontes de referência socioculturais expandem as possibilidades de identificações e pertencimentos juvenis, as biografias e os projetos de vida. Destaca-se que hoje a participação simultânea dos jovens em esferas socializadoras variadas e multifacetadas, como a família, a escola, as mídias, as ruas, grupos religiosos, grupos de subculturas juvenis e no trabalho, aumentam a sua capacidade de autodeterminação e autonomia porque, embora com pesos relativos em cada fase da trajetória dos jovens, todas elas contribuem para os processos dinâmicos de subjetivação, identificação e escolha. Essa nova configuração social que emerge, e para a qual se pode utilizar a imagem do caleidoscópio, resulta, no caso dos jovens, em uma nova visão sobre o mundo e sua participação nele, seja pelo prisma politico, seja na cultura ou no peso que é dado, ou não, ao futuro da vida adulta.

Quando comparados a gerações anteriores, marcadas pela forte atuação de confronto político, os jovens contemporâneos são representados genericamente como apáticos e descompromissados, o que pode, porém, ser facilmente refutado pelos movimentos juvenis antiglobalização ou pelas revoltas estudantis que voltam à cena em várias partes do mundo. Essa suposta apatia também não é confirmada pelos autores que trabalham com narrativas juvenis, nas quais transparece a inconformidade com agendas políticas e culturais engessadas e homogeneizantes, o que faz com que parte 
dos jovens procure alternativas mais microscópicas de resistência, de estar e de agir no mundo.

Assim, na pauta de reivindicações de algumas das microculturas juvenis contemporâneas pode não prevalecer mais um projeto amplo de reformulação social, mas há claramente o desejo de respeito à pluralidade e coexistência cultural, à individualidade e particularidade das tribos; ou seja, exige-se a viabilidade de uma nova forma de existir singular, autêntica e livre que demanda, por parte dos jovens, um processo de constante experimentação (com seus riscos incluídos) de estilos de vida, valores éticos, prioridades sociais e de vida, recursos de expressão e comportamentos que podem se dar, inclusive, em circuitos marginais.

Se entre os valores éticos da juventude contemporânea prevalecem a vontade de ultrapassar os limites, o princípio do prazer lúdico e festivo e a supervalorização do presente e da efemeridade, resta perguntar como pensar os projetos de vida dos jovens. Nessa discussão, dois pontos são importantes: o processo de maturidade e a concepção que temos do que é ser adulto; e os processos de autonomia, liberdade e independência dos jovens, dados os limites estruturais e conjunturais atuais.

A representação recorrente sobre fase adulta implica em pensarmos os adultos como seres completos que já teriam atingido certos indicadores de maturidade como o casamento, o trabalho, a autonomia financeira, em oposição ao jovem ainda em construção. Tais indicadores, até poucas décadas atrás, serviram de roteiro programático para os jovens que deveriam galgar esses patamares lineares até, finalmente, atingir maiores graus de liberdade. Entretanto, com a moratória juvenil, que implica em maior tempo de escolarização e aumento do período que os jovens permanecem com os pais, além da falta de empregos para esse segmento social, torna-se importante discutir a distância entre a intenção imbuída em um projeto de vida e as restrições, de várias ordens, para pô-lo em prática. Assim, os jovens contemporâneos podem ter maior autonomia para elaborar seu projeto de vida, mas encontram constrangimentos, materiais ou simbólicos, que limitam a liberdade de ação, comprometendo seu grau de independência, como o constrangimento financeiro, por exemplo. Mas esse ainda é um espaço em aberto para novas pesquisas e torna-se importante verificar, nesse sentido, os papéis que instâncias socializadoras como a família e a escola assumem 
em projetos de emancipação de jovens, como entendem essa emancipação e com quais conteúdos representam a fase adulta hoje.

Além desses novos investimentos teóricos e empíricos, os artigos finais do livro propõem uma pauta de pesquisas que ainda precisa ser trilhada, incluindo-se, por exemplo, as relações que a juventude e as instâncias socializadoras estabelecem com as questões étnicas, de gênero e de sexualidade, e que ajude a aprofundar o conhecimento sobre a diversidade cultural e como ela perpassa, concretamente, o cotidiano juvenil.

Por conta da magnitude da empreitada desse livro, fica aqui o convite para que ele seja lido por aqueles que se interessam pela escola, pela família e pela juventude; mas fica também o convite para que os organizadores incluam, em próximo evento, pesquisadores e educadores que abordem, especificamente no contexto brasileiro, a forma como família, escola e juventude se articulam em contextos culturais ainda pouco investigados, como o meio rural e os espaços de composição étnica, como os de quilombolas e indígenas, para os quais, inclusive, há políticas educacionais e culturais específicas.

Recebido: $19 / 07 / 2012$

Aprovado: 27/12/2012

Universidade Federal de Viçosa

Departamento de Economia Rural

Av. P. H. Rolfs, s/n, Campus Universitário

CEP $36570-000$

Viçosa, MG

Brasil 